\title{
The JIBS 2018 Decade Award: Comparing capitalisms: Understanding institutional diversity and its implications for international business
}

\author{
Alain Verbeke \\ Haskayne School of Business, University of \\ Calgary, Calgary, Canada \\ Correspondence: \\ A Verbeke, Haskayne School of Business, \\ University of Calgary, Calgary, Canada \\ e-mail: alain.verbeke@haskayne.ucalgary.ca
}

Journal of International Business Studies (2019) 50, I-3. https://doi.org/ | 0.1057/s41267-018-0205-I

The Selection Committee for the JIBS Decade Award was pleased to recommend the presentation of the 2018 JIBS Decade Award, recognizing the most influential article published in JIBS ten years ago, to Gregory Jackson (Free University Berlin) and Richard Deeg (Temple University), for their 2008 article, "Comparing capitalisms: Understanding institutional diversity and its implications for international business" (JIBS, 39(4): 540-561).

The award, sponsored by JIBS' publisher Palgrave Macmillan, is designed to recognize the most influential paper published in JIBS ten years prior and is presented at the annual AIB conference. In order to be considered for the JIBS Decade Award, an article must be one of the five most cited articles published in JIBS for the year being considered.

The 2018 Selection Committee members were Keith D. Brouthers (Chair, King's College, London), the current AIB Program Chair JT Li (Hong Kong University of Science and Technology), and immediate past AIB Program Chair Sarianna Lundan (University of Bremen). JIBS Editor-in-Chief Alain Verbeke was an ex officio, non-voting committee member. The Selection Committee examined total citations, total number of journals citing the paper, and total number of leading journals (excluding JIBS) citing the paper to determine the top five most cited articles. The Committee read and discussed the top five nominees and then voted on the winning article.

In recommending the award-winning article, the Committee noted that: "Jackson \& Deeg (2008) examine the construct of institutions from the comparative capitalism (CC) and international business (IB) perspectives. They are thoughtful and go much 
beyond a synthetic review. They provide insights and directions for research on institutional changes and institutional entrepreneurship. While it was not the most widely cited paper in the year, it was among the top five and provides new theoretical insights into an area of research (institutional theory) that is central to the international business area.

"Jackson and Deeg offer a very thoughtful and comprehensive review of the different institutional perspectives that are of relevance to IB. It presents a balanced and well-considered view of institutional theory from the sociological and political science perspectives, and contrasts that with the view on institutions from the IB literature, which owes more to economic approaches. It is sensitive to the limits of institutional analysis, and it is pointing the way to the future in the discussion on institutional change and the role of MNEs as institutional entrepreneurs.

"Overall, this paper offers an interesting comparison of two distinct approaches to institutions and how they impact the strategies of firms. It contrasts and compares the IB approach with a CC approach offering insights from both that can help us improve our understanding of how institutions change and how MNEs deal with them. Notably, two concepts can aid IB scholars as we try to understand the impact of national institutions on firm behavior. First, the concept of institutional dynamics explores how governments and firms impact and deal with changes in national institutions. This should be of primary importance to the large number of scholars looking at activities into and out of emerging markets, as these markets have very dynamic institutional settings. Second, the concept of institutional configurations suggests that instead of thinking of the institutional environment being composed of regulative, normative and cognitive components we need to look for how the configurations of these components work together within each nation/state. By conceptualizing and testing institutions as a bundle of factors (instead of different components) we can gain greater insights about how MNEs can use the variety of institutions offered in different countries to support an overall strategy.

"For all these reasons, the selection committee recommends the Jackson \& Deeg (2008) paper, which has become a widely cited and highly impactful article, for the 2018 JIBS Decade Award".
In fairness to mainstream IB research, the question arises whether any new, generalizable predictions can be derived from adopting a "thicker conception" of institutions, as compared to what mainstream IB theory (such as internalization theory) can predict. Here, Jackson and Deeg explicitly reject a reductionist or grand theory type approach, which is the essence of both modern IB theory and most of the influential work in the broader social sciences.

A related question is whether the CC approach contributes to an improved understanding of the behavior of internationally operating firms. The answer to this question is unambiguously positive. Home and host country institutions matter, as recognized in almost any IB case study taught in business schools. However, it is unclear whether the CC approach has more descriptive or explanatory power than competing approaches. For example, CC-based analysis falls somewhat short of the rich institutional detail provided by IB historical analysis. Even configurational analyses in the CC sphere can typically not match the insight provided by full-fledged business cases covering the history of firms and their interactions with changing institutions. Wilkins \& Hill's (1964) brilliant exposé "American Business Abroad: Ford on Six Continents", retracing the history of one MNE over the first 60 years of its existence, is a case in point. It also remains unclear what learning can be derived from CC, e.g., in terms of guidelines for management or public policy makers that would be valid across geographies and over long periods of time.

Institutions are complex and evolve as configurations. These institutions also co-evolve with firms. But modern IB theory explicitly addresses issues of resource bundling, with only non-location bound firm-specific advantages being transferable across borders. Location-bound firm-specific advantages are typically over-embedded in the homecountry institutional context. The need therefore arises to complement extant reservoirs of $\mathrm{MNE}$ resources with new resources found in host countries. Host country institutions determine whether, and in what form, these requisite complementary resources can be accessed. Institutional differences and similarities between home and host countries can affect the scope and the challenges associated with novel resource bundling processes. Firms will be influenced by host country institutions and will either try to institutionalize their own governance 
approaches, or will engage in national responsiveness. A very large number of IB studies has addressed the above issues in considerable depth, without relying on CC.

The IB field would likely benefit from analyses being conducted through the use of alternative lenses: CC approaches could compete with mainstream IB approaches, so that an objective assessment could be made, when analyzing specific empirical phenomena, as to which approach is comparatively superior in terms of predictive, explanatory and descriptive power, and in terms of providing useful guidance to managers of internationally operating firms.

\section{REFERENCES}

Jackson, G., \& Deeg, R. 2008. Comparing capitalisms: Understanding institutional diversity and its implications for international business. Journal of International Business Studies, 39(4): 540-561.
At the AIB Annual Meeting in Minneapolis, Minnesota, in June 2018, Professor Deeg, along with invited discussants Sarianna Lundan (University of Bremen), JT Li (HKUST) and Birgitte Grogaard (BI Norwegian Business School), made a retrospective presentation of the work and discussed where the field has progressed and where it should go next in studying institutions.

What follows in this issue are the authors' written Retrospective, together with the discussants' and co-authors' Commentaries, based on that AIB 2018 session. For the original 2008 article, please visit www.jibs.net, where it is available to download, along with all other past Decade Award winners.

Wilkins, M., \& Hill, F. E. 1964. American business abroad: Ford on six continents. Detroit, MI: Wayne State University Press. 